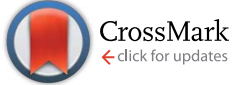

Cite this: RSC Adv., 2015, 5, 20256

Received 6th January 2015

Accepted 27th January 2015

DOI: $10.1039 / \mathrm{c} 5 \mathrm{ra00247h}$

www.rsc.org/advances

\section{Nanoparticles-decorated coal tar pitch-based carbon foam with enhanced electromagnetic radiation absorption capability}

\begin{abstract}
Rajeev Kumar, Ashish Gupta and Sanjay R. Dhakate*
In the present study, to replace existing high-density radar-absorbing materials (RAM) for civil and military aerospace applications, lightweight coal tar pitch-based carbon foam (CFoam) was developed by a sacrificial template technique. The CFoam was decorated with $\mathrm{Fe}_{3} \mathrm{O}_{4}$ and $\mathrm{ZnO}$ nanoparticles to improve electromagnetic (EM) radiation absorption to make it useful as RAM. To ascertain the effect of the decorated nanoparticles on the CFoam, it was characterized by scanning electron microscopy, $\mathrm{X}$-ray diffraction, a vector network analyzer and a vibration sample magnetometer. It was observed that $\mathrm{Fe}_{3} \mathrm{O}_{4}$ and $\mathrm{Fe}_{3} \mathrm{O}_{4}-\mathrm{ZnO}$ nanoparticles have a positive effect on the overall properties of CFoam. The compressive strength of CFoam increases by $22 \%$ and its thermal stability increases by $100{ }^{\circ} \mathrm{C}$, whereas its electrical conductivity decreases by almost $25 \%$. The total shielding effectiveness (SE) of CFoam increases from $-25 \mathrm{~dB}$ to -54 and $-56 \mathrm{~dB}$, respectively, for $\mathrm{Fe}_{3} \mathrm{O}_{4}$ - and $\mathrm{Fe}_{3} \mathrm{O}_{4}-\mathrm{ZnO}$ nanoparticlesdecorated CFoam. The enhancement in total SE for $\mathrm{Fe}_{3} \mathrm{O}_{4}-$ and $\mathrm{Fe}_{3} \mathrm{O}_{4}-\mathrm{ZnO}$-coated CFoam is basically due to the contribution of absorption losses by -42 and $-45 \mathrm{~dB}$. The $\mathrm{Fe}_{3} \mathrm{O}_{4}$ and $\mathrm{Fe}_{3} \mathrm{O}_{4}-\mathrm{ZnO}$ coatings increase surface resistance and magnetic properties because the ferromagnetic nanoparticles act as tiny dipoles, which become polarized in the presence of an EM field and result in the better absorption of EM radiation. This clearly demonstrates that decorated nanoparticles on conducting lightweight CFoam are useful as RAM for different applications to attenuate EM radiation.
\end{abstract}

\section{Introduction}

In the modern technological world, scientists are constantly in search of new materials to replace existing high-density radarabsorbing materials (RAM) for civil and military aerospace applications. In these applications, it is usually important for aircraft and ships to suppress microwave reflection to improve their combat survivability. The absorption of electromagnetic energy in a medium between the radar and a protected target by the use of RAM is one approach to reduce the radar signatures of targets. ${ }^{1}$ RAM are classified into two categories as magnetic and dielectric absorbing materials. The magnetic absorbers depend on the magnetic hysteresis effect, which is produced in magnetic materials such as ferrites. However, the densities of magnetic materials are generally high and the absorbing bandwidths of magnetic absorbers are usually narrow. On the other hand, dielectric materials are lightweight but do not match the absorptivity of magnetic absorbers. ${ }^{2-4}$ These two types of materials have different advantages and disadvantages when applied as absorbers. They can be used together as a composite, where the magnetic material is usually the base, but the high density of

Physics and Engineering of Carbon, Division of Materials Physics and Engineering, CSIR-National Physical Laboratory, Dr K. S. Krishnan Marg, New Delhi-110012, India.E-mail:dhakate@mail.nplindia.org; Tel: +910911145608257 the material is still of great concern. Therefore, to meet the desired requirements, many materials have been singled out or synthesized; among them, carbon materials have been considered as the most promising candidates since World War II. ${ }^{5}$ Carbon-based materials are available naturally or synthesized from organic and inorganic precursors. The physical, mechanical, electrical and thermal properties of carbon materials can be tailored by controlling the processing parameters. Generally, technologists and scientists are looking for highly efficient, thermally conducting and lightweight EMI shielding materials, particularly for aerospace transportation vehicles and space structural applications. Among the different carbon materials, lightweight carbon foam (CFoam) has emerged as a promising candidate for EMI shielding owing to its outstanding properties such as low density, large surface area with an open cell wall structure, good thermal/electrical transport properties and mechanical stability. ${ }^{6,7}$ Lightweight CFoam is a sponge-like rigid high-performance engineering material in which carbon ligaments are connected to each other. In the early days, CFoam was prepared from thermosetting polymeric materials by heat treatment under a controlled atmosphere. ${ }^{8}$ Later on, coal tar and petroleum pitches were used for CFoam synthesis. ${ }^{9}$ The foams derived from organic polymers and pitches have low thermal conductivity, and these are predominantly used as thermal insulating materials. ${ }^{10-14}$ To develop crystalline CFoam with high 
electrical and thermal conductivity, it is generally prepared from mesophase pitch by a high-temperature and high-pressure foaming technique. ${ }^{15,16}$ This is an expensive process; therefore, in the present study, using a simple sacrificial template ${ }^{17}$ technique, CFoam is developed from modified coal tar pitch. ${ }^{18}$ In electrically conductive CFoam, the electromagnetic (EM) shielding effectiveness (SE) is dominated by reflection losses rather than absorption. ${ }^{\mathbf{1 9 , 2 0}}$ Therefore, to improve microwave absorption in CFoam, it is heat-treated at a lower temperature; thus, it will be dielectric or will have low electrical conductivity. However, to use CFoam as RAM in civil and military aerospace applications, the material should be thermally stable and conductive, so that the heat generated due to the absorption of electromagnetic radiation should not damage electronic components in the system. However, CFoam processing carried out at low temperature does not give adequate thermal stability and conductivity.

Therefore, it is necessary to coat or decorate CFoam with magnetic/dielectric nanomaterials, so that CFoam can act as an excellent microwave-absorbing material with the requisite thermal stability and conductivity, in which microwaves can be absorbed due to the different interactive energy dissipation processes of polarization and magnetization. ${ }^{21}$ With this aim, in the present investigation coal tar pitch-derived CFoams were developed by a sacrificial template technique and heat-treated at $1000{ }^{\circ} \mathrm{C}$ in an inert atmosphere. These foams were coated by a ferromagnetic ferrofluid and dielectric zinc oxide ( $\mathrm{ZnO}$ ) nanoparticles to improve their radar emission absorption. The ferrofluid is a suspension of $\mathrm{Fe}_{3} \mathrm{O}_{4}$ nanoparticles in an organic solvent. Nanosized $\mathrm{Fe}_{3} \mathrm{O}_{4}$ is a type of magnetic functional nanomaterial, which has been widely used as a microwave radiation absorber. ${ }^{22,23}$ To ascertain the effect of $\mathrm{Fe}_{3} \mathrm{O}_{4}$ and $\mathrm{ZnO}$ coatings on CFoam, coated and uncoated CFoams were characterized by scanning electron microscopy, X-ray diffraction, a vector network analyzer and a vibration sample magnetometer, for compressive strength and electrical conductivity.

\section{Experimental}

\subsection{Development of carbon foam}

The CFoam was developed by a sacrificial template technique from modified coal tar pitch. The starting coal tar pitch has softening point of $86.6{ }^{\circ} \mathrm{C}$, quinoline insoluble (QI) of $0.2 \%$, toluene insoluble (TI) content of $15.9 \%$ and coking value of $47.6 \%$. The coal tar pitch was modified by heat treatment at $400{ }^{\circ} \mathrm{C}$ for 5 hours. The modified coal tar pitch has softening point of $236{ }^{\circ} \mathrm{C}$, QI content of $23.6 \%$, TI content of $63.0 \%$ and coking value of $78.5 \%$. A water slurry of modified coal tar pitch with 3\% polyvinyl alcohol (PVA) was impregnated into a polyurethane foam (procured from S. G. \& Company, New Delhi, with density $0.030 \mathrm{~g} \mathrm{~cm}^{-3}$ and average pore size $0.45 \mathrm{~mm}$ ) template under vacuum. The modified coal tar pitch-impregnated polyurethane foam was converted into CFoam by several heat treatments in air as well as in an inert atmosphere up to $1000{ }^{\circ} \mathrm{C}^{24}$ Initially, the modified coal tar pitch-impregnated foams were heat-treated at the rate of $1{ }^{\circ} \mathrm{C} \min ^{-1}$ to $275{ }^{\circ} \mathrm{C}$ in nitrogen atmosphere for $1 \mathrm{~h}$, followed by oxidation and stabilization in air atmosphere at a temperature of $300{ }^{\circ} \mathrm{C}$. The stabilized foam was carbonized in a tubular high-temperature furnace at $1000{ }^{\circ} \mathrm{C}$ with a heating rate of $10{ }^{\circ} \mathrm{C} \mathrm{h}^{-1}$ in inert atmosphere.

$\mathrm{Fe}_{3} \mathrm{O}_{4}$ nanoparticles were synthesized by a well-established chemical co-precipitation method. ${ }^{25,26}$ A solution containing ferric $\left(\mathrm{Fe}^{3+}\right)$ chloride and ferrous $\left(\mathrm{Fe}^{2+}\right)$ sulfate was introduced in deionized water. The mixture was stirred for an hour and oleic acid was added as a surfactant. A base (20-25 $\mathrm{ml}$ ammonia solution) was added at $80{ }^{\circ} \mathrm{C}$, maintaining the $\mathrm{pH}$ at 9-10. Nanoparticles were magnetically decanted and washed several times with deionized water to remove unwanted residues of salt. To obtain a ferrofluid, the wet slurry was dispersed in kerosene and centrifuged. $\mathrm{ZnO}$ nanoparticles were prepared by the thermal evaporation of zinc acetate ${ }^{27}$ at $60-70{ }^{\circ} \mathrm{C}$ with slow heating. The CFoam was coated with ferrofluid solution and another sample was coated with ferrofluid-zinc oxide solution in weight ratios of $0.5: 0.5$. After coating with ferrofluid and ferrofluid-zinc oxide nanoparticles, these CFoams were heattreated at $650{ }^{\circ} \mathrm{C}$ for 10 minutes in an inert atmosphere. The process for the synthesis of pure CFoam and $\mathrm{Fe}_{3} \mathrm{O}_{4^{-}}$and $\mathrm{Fe}_{3} \mathrm{O}_{4}-\mathrm{ZnO}$-coated CFoam is shown in Fig. 1. The uncoated and coated CFoams were designated as follows: uncoated CFoam as (CF-U), $\mathrm{Fe}_{3} \mathrm{O}_{4}$-coated CFoam as $\left(\mathrm{CF}-\mathrm{Fe}_{3} \mathrm{O}_{4}\right)$ and $\mathrm{Fe}_{3} \mathrm{O}_{4}-\mathrm{ZnO}$-coated CFoam as $\left(\mathrm{CF}-\mathrm{Fe}_{3} \mathrm{O}_{4}-\mathrm{ZnO}\right)$.

\subsection{Characterization}

The weight percentage of nanoparticles in CFoam was evaluated by a thermogravimetric analyzer (TGA, Mettler Toledo). The nanoparticle-decorated CFoam was heated to $1000{ }^{\circ} \mathrm{C}$ in an air atmosphere; during heat treatment, carbon would be oxidized completely and the residue remaining at the end of the heat treatment is in the form of nanoparticles. The bulk density of the foam was measured using the ASTM standard (ASTM C559); bulk density is a ratio of the weight of the CFoam in air to its volume. The weight of the CFoam was measured by a digital balance (model ME 40290) and the volume of the CFoam was calculated by measuring its dimensions with the help of digital vernier calipers. The compressive strength of all the CFoams were measured on a universal testing machine, Instron model 4411, as per the ASTM standard. The thermal conductivity of CFoam was measured by the laser flash method with a xenon laser as the source in a thermo flash line 2003 instrument (Anter Corporation, USA). By the laser flash method, the thermal diffusivity and specific heat of each sample were measured at $25{ }^{\circ} \mathrm{C}$. The thermal conductivity was then calculated from the equation $\alpha=k /\left(\rho C_{\mathrm{p}}\right)$, where $\alpha$ is the thermal diffusivity, $k$ is the thermal conductivity, $C_{\mathrm{p}}$ is the specific heat and $\rho$ is the density of the foam.

Raman spectra of CFoam samples were recorded using a Renishaw inVia Raman spectrometer (UK) with a laser as an excitation source at $514 \mathrm{~nm}$. The crystal structure of CFoams was studied by X-ray diffraction (XRD, Bruker D8 Advance diffractometer) using $\mathrm{Cu} \mathrm{K}_{\alpha}$ radiation $(\lambda=1.5418 \AA)$. The surface morphology of the samples was observed by a scanning electron microscope (SEM, Leo model S-440). The electrical conductivity of CFoam was measured by a d.c. four-probe contact method 


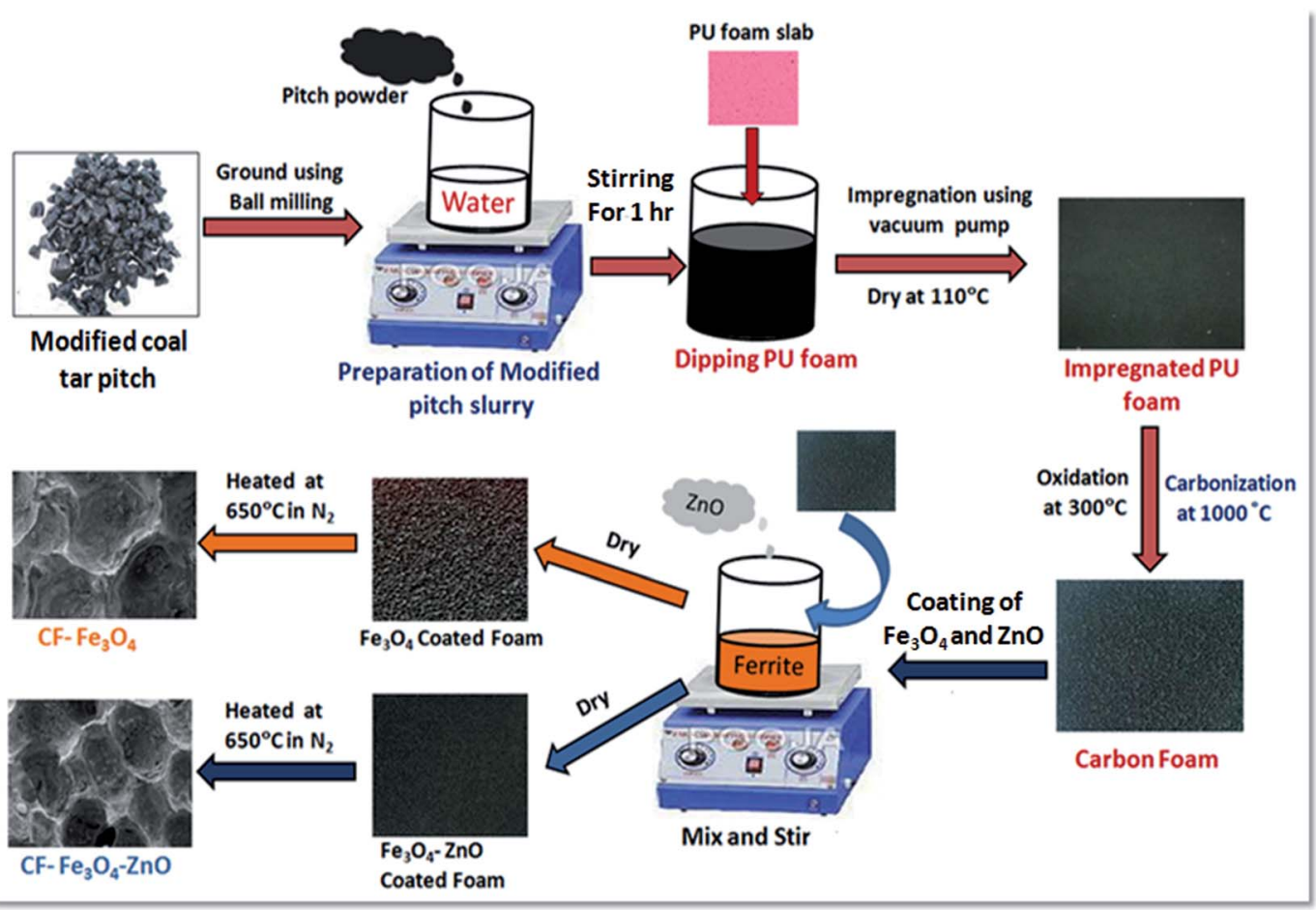

Fig. 1 Process for synthesis of pure CFoam and $\mathrm{Fe}_{3} \mathrm{O}_{4}-$ and $\mathrm{Fe}_{3} \mathrm{O}_{4}-\mathrm{ZnO}$-coated CFoam.

using a Keithley 224 programmable current source for providing current. The voltage drop was measured by a Keithley 197A autoranging digital microvoltmeter. The values reported here are averaged over six readings of voltage drops for different portions of the sample. The electromagnetic interference shielding effectiveness (EMI-SE) was measured by a waveguide using a vector network analyzer (VNA E8263B, Agilent Technologies). Rectangular samples with a thickness of $2.75 \mathrm{~mm}$ were placed inside the cavity of a sample holder, which matched the internal dimensions of the X-band $(8.4-12.4 \mathrm{GHz})$ waveguide. The sample holder was placed between the flanges of the waveguide connected between the two ports of the VNA. A full two-port calibration was performed using a quarter-wavelength offset and terminations and keeping the input power level at -5.0 $\mathrm{dBm}$. The magnetic properties of the foam samples were measured by a vibration sample magnetometer (VSM) model 7304 (Lake Shore Cryotronics Inc., USA) with a maximum magnetic field of $1.2 \mathrm{~T}$ vibrating horizontally at a frequency of 76 $\mathrm{Hz}$. The thermal stability of the CFoam was investigated by TGA in an air atmosphere at the rate of $10{ }^{\circ} \mathrm{C} \mathrm{min}^{-1}$.

\section{Results and discussion}

The physical and mechanical properties of CFoam are reported in Table 1. The bulk density of CF-U heat-treated at $1000{ }^{\circ} \mathrm{C}$ is $0.52 \mathrm{~g} \mathrm{~cm}^{-3}$, whereas the bulk density of $\mathrm{Fe}_{3} \mathrm{O}_{4}$ and $\mathrm{Fe}_{3} \mathrm{O}_{4}-\mathrm{ZnO}$ nanoparticles-coated CFoams $\left(\mathrm{CF}-\mathrm{Fe}_{3} \mathrm{O}_{4}\right.$ and $\left.\mathrm{CF}-\mathrm{Fe}_{3} \mathrm{O}_{4}-\mathrm{ZnO}\right)$ increases to $0.58 \mathrm{~g} \mathrm{~cm}^{-3}$. The thin coatings of nanoparticles help to increase the bulk density of CFoam by more than $10 \%$. The increase in bulk density has a positive effect on the mechanical properties of CFoam.
Table 1 Properties of CFoam

\begin{tabular}{llll}
\hline Properties & $\mathrm{CF}-\mathrm{U}$ & $\mathrm{CF}-\mathrm{Fe}_{3} \mathrm{O}_{4}$ & $\mathrm{CF}-\mathrm{Fe}_{3} \mathrm{O}_{4}-\mathrm{ZnO}$ \\
\hline Bulk density $\left(\mathrm{g} \mathrm{cm}^{-3}\right)$ & 0.52 & 0.58 & 0.58 \\
Compressive strength $(\mathrm{MPa})$ & 7.5 & 8.9 & 9.2 \\
Electrical conductivity $\left(\mathrm{S} \mathrm{cm}^{-1}\right)$ & 55.0 & 42.0 & 40.0 \\
Thermal conductivity $\left(\mathrm{W} \mathrm{m}^{-1} \mathrm{~K}^{-1}\right)$ & 20.0 & - & -
\end{tabular}

The nanoparticles are embedded in terms of weight percentage in both the cases: in $\mathrm{Fe}_{3} \mathrm{O}_{4}$-embedded foam, the nanoparticle content is $9 \%$ by weight and in $\mathrm{Fe}_{3} \mathrm{O}_{4}-\mathrm{ZnO}$ embedded foam the nanoparticle content is $10 \%$ by weight, as confirmed by TGA. The densities of $\mathrm{Fe}_{3} \mathrm{O}_{4}$ and $\mathrm{ZnO}$ nanoparticles are 4.8 and $5.6 \mathrm{~g} \mathrm{~cm}^{-3}$, the enhancement in density is therefore almost the same (an $11.5 \%$ increase in density) for nanoparticles-embedded carbon foam.

The compressive strength of $\mathrm{CF}-\mathrm{U}$ is $7.50 \mathrm{MPa}$ and that of $\mathrm{CF}-\mathrm{Fe}_{3} \mathrm{O}_{4}$ is $8.90 \mathrm{MPa}$, while in the case of $\mathrm{CF}-\mathrm{Fe}_{3} \mathrm{O}_{4}-\mathrm{ZnO}$ foam, the compressive strength increases from 7.50 MPa to 9.20 MPa. Therefore, there is an increase of $22 \%$ in the compressive strength of $\mathrm{Fe}_{3} \mathrm{O}_{4}$ and $\mathrm{Fe}_{3} \mathrm{O}_{4}-\mathrm{ZnO}$ nanoparticles-embedded CFoams. The improvement in the compressive strength of $\mathrm{Fe}_{3} \mathrm{O}_{4}$ - and $\mathrm{Fe}_{3} \mathrm{O}_{4}-\mathrm{ZnO}$ nanoparticles-embedded CFoams is due to the higher compressive strength of the nanoparticles, as well as increases in the density of the foam as a result of the high nanoparticle density (densities of $\mathrm{Fe}_{3} \mathrm{O}_{4}$ and $\mathrm{ZnO}$ nanoparticles are 4.8 and $5.6 \mathrm{~g} \mathrm{~cm}^{-3}$ ). Moreover, the compressive strength of CFoam also depends on its microstructure. The microstructure mainly includes wide ligaments and abundant microcracks. In 
the case of CF-U, a load is transferred through ligaments; therefore, cracks in the ligaments can be responsible for the low load-bearing capacity of CFoam. In the case of $\mathrm{Fe}_{3} \mathrm{O}_{4}$ and $\mathrm{Fe}_{3} \mathrm{O}_{4}$-ZnO-coated CFoam, $\mathrm{Fe}_{3} \mathrm{O}_{4}$ and $\mathrm{ZnO}$ nanoparticles infiltrate into the cracks and are deposited on the ligaments and inside and on the surface of pores, resulting in an increase in bulk density and a reduction in the density of cracks. Thus, in the case of $\mathrm{CF}-\mathrm{Fe}_{3} \mathrm{O}_{4}$ and $\mathrm{CF}-\mathrm{Fe}_{3} \mathrm{O}_{4}-\mathrm{ZnO}$, nanoparticles infiltrate into the cracks and are deposited on the ligaments, which can help in deflecting and carrying an applied load. This accounts for the improvement in the compressive strength of CFoams.

The nanoparticles will affect the electrical conductivity of the CFoam because the conductivity of $\mathrm{Fe}_{3} \mathrm{O}_{4}$ and $\mathrm{ZnO}$ nanoparticles is comparatively less than that of CFoam heat-treated at $1000{ }^{\circ} \mathrm{C}$. The electrical conductivity of CFoam CF-U is 55 $\mathrm{S} \mathrm{cm}^{-1}$ due to delocalized $\pi$ electrons in the carbon network in the coal tar pitch-derived CFoam. However, in the case of $\mathrm{Fe}_{3} \mathrm{O}_{4}$-coated foam $\left(\mathrm{CF}-\mathrm{Fe}_{3} \mathrm{O}_{4}\right)$, electrical conductivity decreases to $42 \mathrm{~S} \mathrm{~cm}^{-1}$ and for $\mathrm{Fe}_{3} \mathrm{O}_{4}-\mathrm{ZnO}$-coated foam, the electrical conductivity is almost the same as the conductivity of $\mathrm{CF}-\mathrm{Fe}_{3} \mathrm{O}_{4}$. The decrease in the conductivity is because $\mathrm{Fe}_{3} \mathrm{O}_{4}$ and $\mathrm{ZnO}$ inhibit the conduction path of electrons. Moreover, $\mathrm{Fe}_{3} \mathrm{O}_{4}$ and $\mathrm{ZnO}$ were coated mostly on the surface and infiltrated into the open pores and as a consequence, the surface resistance of CFoam increases. The conduction path decreases due to the interactions of magnetic and dielectric materials with carbon during heat treatment above $600{ }^{\circ} \mathrm{C}$. Thermal conductivity is also an important criterion for quick heat dissipation in CFoam used in civil and military aerospace vehicles to protect them from the thermal heating of electronic power systems. The thermal conductivity of a material is governed by its lattice vibrations. The thermal conductivity of CFoam (CF-U) is in the range $20 \mathrm{~W} \mathrm{~m}^{-1} \mathrm{~K}^{-1}$ and is influenced by the structure of the foam, in which most of the heat is transferred by the ligaments and cell wall. Fig. 2(a-c) illustrate the SEM images of CFoam. In the case of CF-U (Fig. 2(a)), the cells are not exactly spherical in shape and the distribution of cells is not uniform. The cell geometry is significantly influenced by the morphology of the template foam. Not all the cells are open, some of them have incomplete cell membranes and each cell is partly sealed off from its neighbors, i.e., by ligaments. However, in $\mathrm{CF}-\mathrm{Fe}_{3} \mathrm{O}_{4}$ (Fig. 2(b)), $\mathrm{Fe}_{3} \mathrm{O}_{4}$ particles are coated on ligaments and infiltrated into pores, and some of the nanoparticles are agglomerated, resulting in bigger particles.
The size of $\mathrm{Fe}_{3} \mathrm{O}_{4}$ nanoparticles (10-15 nm) is shown in Fig. 3(a). In the case of $\mathrm{CF}-\mathrm{Fe}_{3} \mathrm{O}_{4}-\mathrm{ZnO}$ (Fig. 2(c)), both types of nanoparticles are coated on ligaments and infiltrated inside pores, but the extent of agglomeration is less as compared to $\mathrm{CF}-\mathrm{Fe}_{3} \mathrm{O}_{4}$. It is interesting to note that the larger particle size of $\mathrm{ZnO}$ (Fig. 3(b)) limits the agglomeration of $\mathrm{Fe}_{3} \mathrm{O}_{4}$ in the case of $\mathrm{CF}-\mathrm{Fe}_{3} \mathrm{O}_{4}-\mathrm{ZnO}$.

Fig. 4(a-d) shows the XRD curves of $\mathrm{CF}-\mathrm{U}, \mathrm{Fe}_{3} \mathrm{O}_{4}$ and $\mathrm{ZnO}$ nanoparticles, $\mathrm{CF}-\mathrm{Fe}_{3} \mathrm{O}_{4}$ and $\mathrm{CF}-\mathrm{Fe}_{3} \mathrm{O}_{4}-\mathrm{ZnO}$. In the case of CF$\mathrm{U}$ (Fig. 4(a)), carbon derived from graphitized coal tar pitch exhibits three peaks at $2 \theta=24.98^{\circ}, 43.44^{\circ}$ and $79^{\circ}$ corresponding to the carbon of 002, 101 and 110 lattice planes. The broad peak (002) interlayer spacing ( $d$-spacing) corresponds to $d_{002}=0.3566 \mathrm{~nm}$, indicating carbonized disordered carbon. The XRD pattern of the $\mathrm{Fe}_{3} \mathrm{O}_{4}$ nanoparticles (Fig. 4(b)) appears considerably identical to that of pure magnetite and matches well with JCPDS no. 19-0629, which indicates that the sample has a cubic crystal system. ${ }^{28}$ The mean crystallite size $(10.5 \mathrm{~nm})$ is calculated from the XRD curve according to the line width of the (311) plane diffraction peak using the Scherrer equation. Fig. 4(b) also shows the XRD pattern of the $\mathrm{ZnO}$ nanoparticles. The peaks at $2 \theta$ values of $32.1^{\circ}, 34.7^{\circ}, 36.6^{\circ}, 47.9^{\circ}, 56.9^{\circ}, 63.2^{\circ}$, $66.7^{\circ}, 68.3^{\circ}$ and $69.4^{\circ}$ correspond to the (100), (002), (101), (102), (110), (103), (200), (112) and (201) planes, which are confirmed by JCPDS no. $36-1451 .^{29}$ The results reveal that the $\mathrm{ZnO}$ nanoparticles are of wurtzite hexagonal-type structure. ${ }^{30}$ Fig. 4(c) shows the XRD curve of $\mathrm{CF}-\mathrm{Fe}_{3} \mathrm{O}_{4}$, which consists of peaks of carbon and $\mathrm{Fe}_{3} \mathrm{O}_{4}$ at $2 \theta$ equal to $25.22^{\circ}, 35.1^{\circ}, 43.26^{\circ}, 44.6^{\circ}$, $53.72^{\circ}, 57.15^{\circ}, 62.55^{\circ}$ and $78.92^{\circ}$. During the heat treatment, interactions between carbon and $\mathrm{Fe}_{3} \mathrm{O}_{4}$ nanoparticles occur at temperatures between 500 and $650{ }^{\circ} \mathrm{C}$, which form $\mathrm{Fe}-\mathrm{C}$ (peak at $43.26^{\circ}$ ).

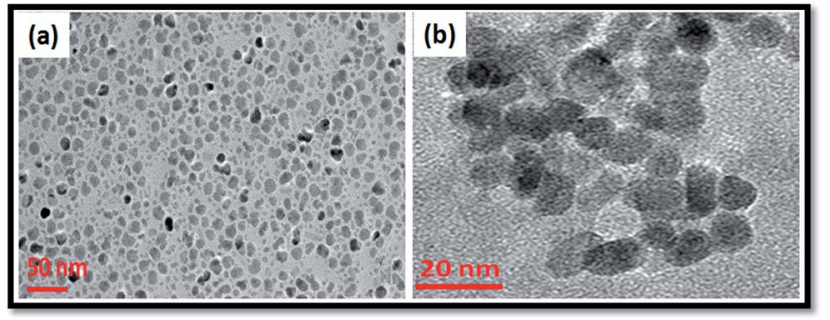

Fig. 3 TEM micrographs of (a) $\mathrm{Fe}_{3} \mathrm{O}_{4}$ and (b) $\mathrm{ZnO}$.

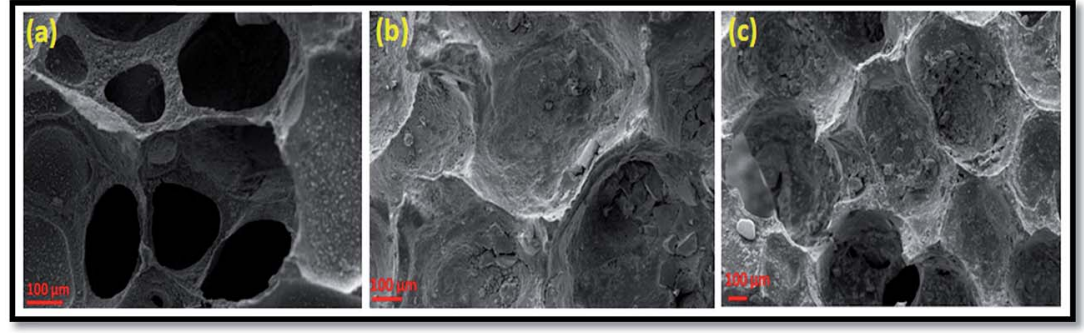

Fig. 2 SEM micrographs of CFoam: (a) CF-U, (b) $\mathrm{CF}-\mathrm{Fe}_{3} \mathrm{O}_{4}$ and (c) $\mathrm{CF}-\mathrm{Fe}_{3} \mathrm{O}_{4}-\mathrm{ZnO}$. 

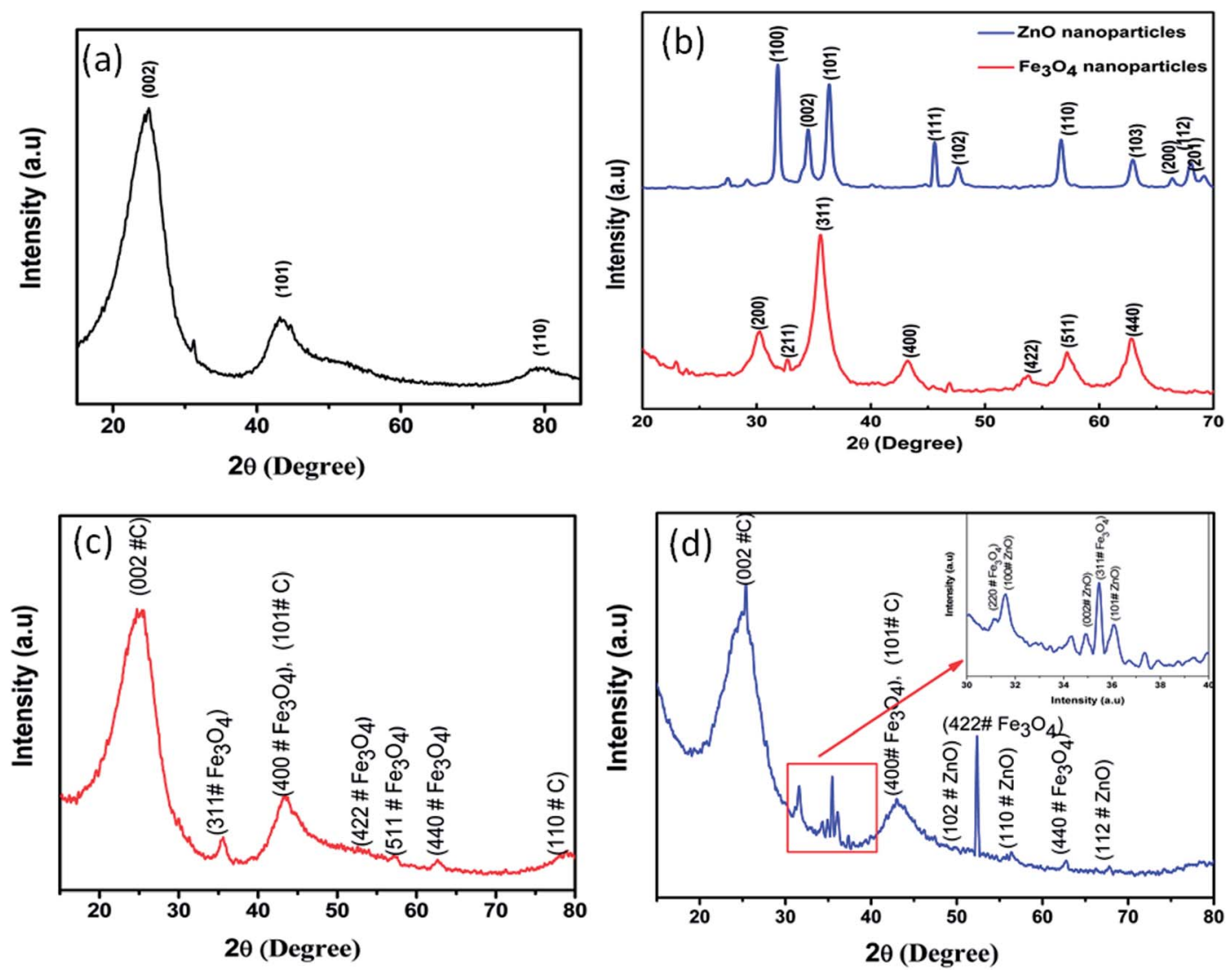

Fig. 4 XRD spectra of (a) $\mathrm{CF}-\mathrm{U}$, (b) $\mathrm{Fe}_{3} \mathrm{O}_{4}$ and $\mathrm{ZnO}$ nanoparticles, (c) $\mathrm{CF}-\mathrm{Fe}_{3} \mathrm{O}_{4}$ and (d) $\mathrm{CF}-\mathrm{Fe}_{3} \mathrm{O}_{4}-\mathrm{ZnO}$.

It is well known that carbon is a reducing agent, which can react with $\mathrm{Fe}-\mathrm{O}$ compounds during heat treatment and the $\mathrm{Fe}-\mathrm{O}$ compounds are transformed into iron carbide. ${ }^{31}$ Moreover, the peaks of $\mathrm{Fe}_{3} \mathrm{O}_{4}$ are shifted to lower diffraction angles, which suggest the successful incorporation of the dopant in the host matrix. In the case of $\mathrm{CF}-\mathrm{Fe}_{3} \mathrm{O}_{4}-\mathrm{ZnO}$ (Fig. 4(d)), it is observed that $\mathrm{ZnO}$ and $\mathrm{Fe}_{3} \mathrm{O}_{4}$ coexist with carbon, which results in a change in the peak positions that has a positive effect on the magnetic and dielectric properties of the CFoam. Therefore, $\mathrm{CF}-\mathrm{Fe}_{3} \mathrm{O}_{4}-\mathrm{ZnO}$ exhibits peaks of amorphous carbon, $\mathrm{Fe}_{3} \mathrm{O}_{4}$ and $\mathrm{ZnO}$ at $2 \theta$ equal to $25.27^{\circ}, 31.3^{\circ}, 35.27^{\circ}, 35.7^{\circ}, 36.12^{\circ}, 42.99^{\circ}$, $52.3^{\circ}, 56.4^{\circ}, 62.7^{\circ}$ and $67.32^{\circ}$, while some of the $\mathrm{ZnO}$ peaks are of relatively low intensity compared to those of carbon and $\mathrm{Fe}_{3} \mathrm{O}_{4}$; therefore, a magnified view (XRD) of $\mathrm{CF}-\mathrm{Fe}_{3} \mathrm{O}_{4}-\mathrm{ZnO}$ at $30-40^{\circ}$ is shown in the inset of Fig. $4(\mathrm{~d})$.

Fig. 5 shows the shielding effectiveness (SE) of CF-U, $\mathrm{CF}-\mathrm{Fe}_{3} \mathrm{O}_{4}$ and $\mathrm{CF}-\mathrm{Fe}_{3} \mathrm{O}_{4}-\mathrm{ZnO}$ in the frequency range of 8.212.4 GHz. It is well known that the properties of CFoam can be influenced by its processing temperature because the structure of carbon materials is modified with increasing temperature during heat treatment process. ${ }^{32}$ As a consequence, there is an increase in the electrical conductivity of carbon materials with increasing processing temperature. In this investigation, the CFoams used are heat-treated to a temperature of $1000{ }^{\circ} \mathrm{C}$, which have considerably a high value of electrical conductivity. Generally, electromagnetic (EM) radiation is reflected from conducting materials. The extent of reflection depends on the electrical conductivity and morphology of shielding materials, while the absorption of EM radiation is controlled by the magnetic and dielectric properties of shielding materials.

The validation of CFoam as a RAM or EM shield can be established by measuring its SE in terms of reflection and absorption losses. The SE of a shielding material is its ability to attenuate EM radiation, which can be expressed in terms of the ratio of incoming (incident) to outgoing (transmitted) power. ${ }^{33}$ The higher values of SE in decibels (dB) signify less energy passes through the shield and most of the energy is absorbed or reflected by the shielding material. The EM attenuation provided by a shield or RAM may depend on three mechanisms: reflection of the wave from the front face of the shield, absorption of the wave as it passes through the shield and multiple reflections of the wave at various interfaces. ${ }^{34}$ Therefore, the total $\mathrm{SE}\left(\mathrm{SE}_{\mathrm{T}}\right)$ of a RAM is attributed to three types of losses, viz. reflection loss $\left(\mathrm{SE}_{\mathrm{R}}\right)$, absorption loss $\left(\mathrm{SE}_{\mathrm{A}}\right)$ and multiple reflection loss $\left(\mathrm{SE}_{\mathrm{M}}\right)$, and can be expressed as follows:

$$
\mathrm{SE}_{\mathrm{T}}(\mathrm{dB})=\mathrm{SE}_{\mathrm{R}}+\mathrm{SE}_{\mathrm{A}}+\mathrm{SE}_{\mathrm{M}}=10 \log \left(P_{\mathrm{t}} / P_{\mathrm{i}}\right)
$$

where $P_{\mathrm{i}}$ and $P_{\mathrm{t}}$ are the power of the incident and transmitted EM waves, respectively. Because $P_{\mathrm{t}}$ is always less than $P_{\mathrm{i}}, \mathrm{SE}_{\mathrm{T}}$ is a negative quantity, and a more negative value means an increase in the magnitude of SE. It is important to note that losses associated with multiple reflections can be ignored $\left(\mathrm{SE}_{\mathrm{M}} \sim 0\right)$ 

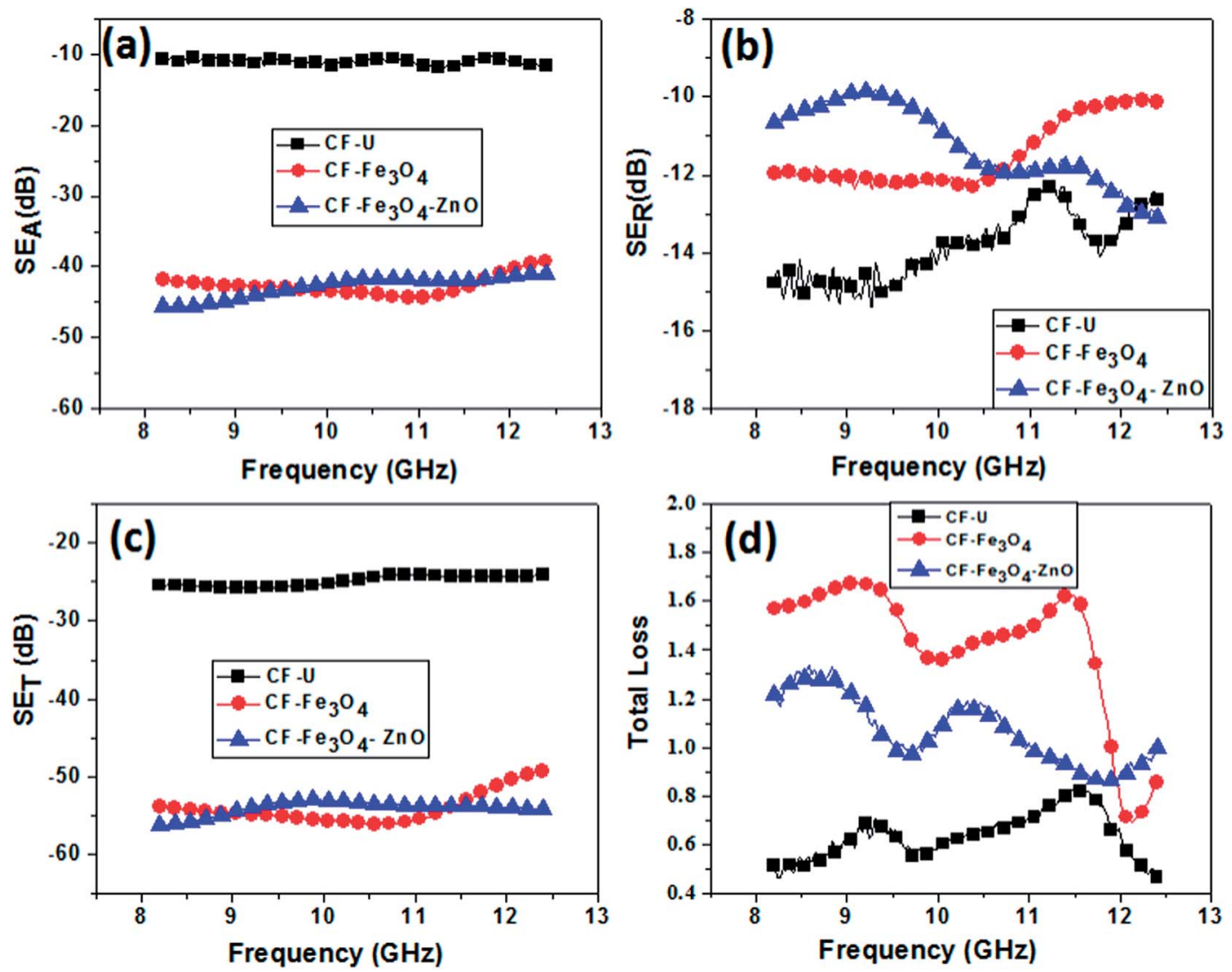

Fig. 5 Shielding effectiveness of CFoam in the frequency range of 8.2-12.4 GHz: (a) $S E_{A}$ (b) $S E_{R}$ (c) $S E_{T}$ and (d) total loss with increasing frequency.

when the SE of an EMI shielding material is more than -10 $\mathrm{dB} ;{ }^{20}$ thus, $\mathrm{SE}$ can be expressed as $\mathrm{SE}_{\mathrm{T}}(\mathrm{dB})=\mathrm{SE}_{\mathrm{R}}+\mathrm{SE}_{\mathrm{A}}$.

Fig. 5 shows the $\mathrm{SE}_{\mathrm{A}}, \mathrm{SE}_{\mathrm{R}}$, and $\mathrm{SE}_{\mathrm{T}}$ of CFoams in the X-band frequency region. It is observed that the $\mathrm{SE}_{\mathrm{A}}$ is almost constant with increasing frequency (Fig. 5(a)), while the $\mathrm{SE}_{\mathrm{R}}$ varies with frequency (Fig. 5(b)), and from Fig. 5(c), it is observed that the total $\mathrm{SE}$ follows the trend of $\mathrm{SE}_{\mathrm{A}}$. The value of $\mathrm{SE}_{\mathrm{T}}$ for $\mathrm{CF}-\mathrm{U}$ is $-25 \mathrm{~dB}$, while in the cases of $\mathrm{CF}-\mathrm{Fe}_{3} \mathrm{O}_{4}$ and $\mathrm{CF}-\mathrm{Fe}_{3} \mathrm{O}_{4}-\mathrm{ZnO}$, it increases to -54 and $-56 \mathrm{~dB}$. It is interesting to note that the $\mathrm{SE}_{\mathrm{T}}$ of $\mathrm{CF}-\mathrm{Fe}_{3} \mathrm{O}_{4}$ and $\mathrm{CF}-\mathrm{Fe}_{3} \mathrm{O}_{4}-\mathrm{ZnO}$ is twice that of CF-U. In the case of CF-U, the $\mathrm{SE}_{\mathrm{R}}(-14 \mathrm{~dB})$ is slightly higher than the $\mathrm{SE}_{\mathrm{A}}$ $(-11 \mathrm{~dB})$. However, the $\mathrm{SE}_{\mathrm{T}}$ in $\mathrm{CF}-\mathrm{Fe}_{3} \mathrm{O}_{4}$ and $\mathrm{CF}-\mathrm{Fe}_{3} \mathrm{O}_{4}-\mathrm{ZnO}$ is governed by absorption losses $\mathrm{SE}_{\mathrm{A}}(-42$ and $-45 \mathrm{~dB})$ and partially by reflection losses $\mathrm{SE}_{\mathrm{R}}(-12$ and $-11 \mathrm{~dB})$. In the case of $\mathrm{CF}-\mathrm{Fe}_{3} \mathrm{O}_{4}-\mathrm{ZnO}$, the presence of $\mathrm{ZnO}$ nanoparticles along with ferrite nanoparticles increases the absorption losses. As reported in the previously discussed section, $\mathrm{ZnO}$ nanoparticles control the agglomeration of $\mathrm{Fe}_{3} \mathrm{O}_{4}$ nanoparticles after coating on the foam $\mathrm{CF}-\mathrm{Fe}_{3} \mathrm{O}_{4}-\mathrm{ZnO}$, which provides a higher surface area and larger interfacial area in comparison to CF-U and $\mathrm{CF}-\mathrm{Fe}_{3} \mathrm{O}_{4}$.

However, $\mathrm{ZnO}$ is a dielectric material, thus the addition of $\mathrm{ZnO}$ with $\mathrm{Fe}_{3} \mathrm{O}_{4}$ to carbon foam influences the electrical conductivity of the carbon foam. Moreover, the reflection component is dependent on electrical conductivity, as shown in the following equation for the SE reflection component:

$$
\mathrm{SE}_{\mathrm{R}}=-10 \log _{10}\left\{\left(\sigma_{\mathrm{T}}\right) /\left(16 \omega \varepsilon_{0} \mu^{\prime}\right)\right\}
$$

As a result, $\mathrm{ZnO}$ contributes to a decrease in electrical conductivity as well as the dielectric constant, and as a consequence, reduce the magnetic properties. (Magnetization, depicted in Fig. 7, is less with $\mathrm{ZnO}$ embedded with $\mathrm{Fe}_{3} \mathrm{O}_{4}$ in carbon foam.) Thus, a decrease in the electrical conductivity of carbon foam decreases the reflection component of carbon foam, resulting in an increase in the absorption component.

To understand the possible mechanism of an increase in absorption of EM radiation, EM parameters, i.e., relative complex permittivity $\left(\varepsilon^{*}=\varepsilon^{\prime}-i \varepsilon^{\prime \prime}\right)$ and relative complex permeability $\left(\mu^{*}=\mu^{\prime}-i \mu^{\prime \prime}\right)$, were measured in the frequency region of $8.2-12.4 \mathrm{GHz}$ for CFoams, which are depicted in Fig. 6(a and b). These obtained complex parameters were estimated from experimental scattering parameters $\left(S_{11}\right.$ and $\left.S_{21}\right)$ by standard Nicolson and Ross theoretical calculations. ${ }^{35}$ The estimated real parts of the EM parameters $\left(\varepsilon^{\prime}, \mu^{\prime}\right)$ are directly associated with the amount of polarization occurring in the material, which symbolizes its storage ability of electric and magnetic energy, while the imaginary parts $\left(\varepsilon^{\prime \prime}, \mu^{\prime \prime}\right)$ signify the dissipated electric and magnetic energy. The complex values of permittivity and permeability typically correspond to attenuation in a medium in which real permittivity and permeability are related to wave propagation rather than attenuation. 

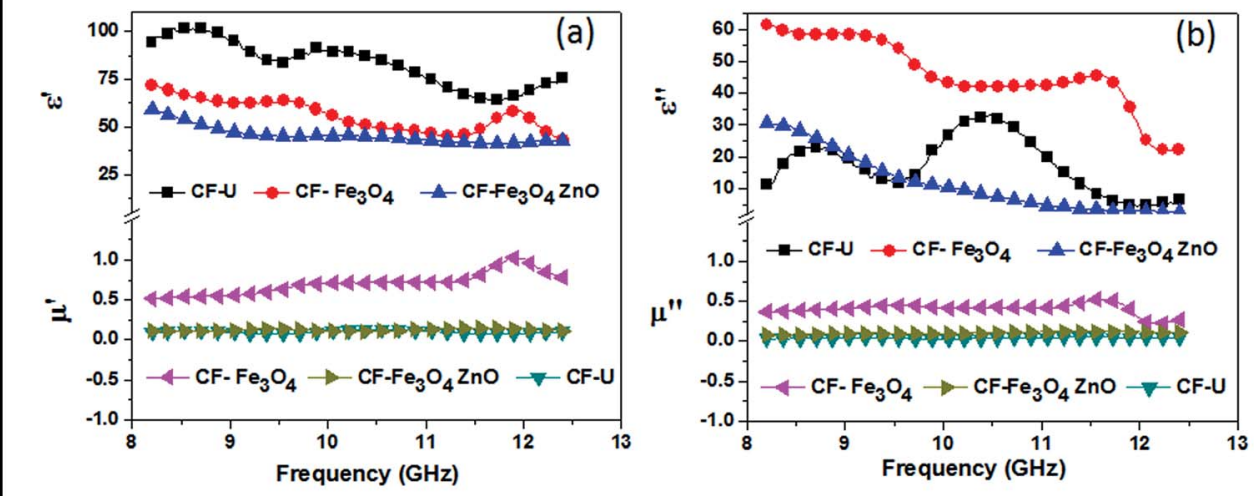

Fig. 6 (a) Real, and (b) Imaginary permittivity and permeability of CFoam.

In this context, as reported above, the effect of $\mathrm{Fe}_{3} \mathrm{O}_{4}$ and $\mathrm{Fe}_{3} \mathrm{O}_{4}-\mathrm{ZnO}$ coating on the real permittivity and permeability is depicted in Fig. 6(a). The real permittivity in all types of CFoams (CF-U, $\mathrm{CF}-\mathrm{Fe}_{3} \mathrm{O}_{4}$ and $\mathrm{CF}-\mathrm{Fe}_{3} \mathrm{O}_{4}-\mathrm{ZnO}$ ) decreases slightly with an increase in frequency. The maximum value of real permittivity is in the case of $\mathrm{CF}-\mathrm{U}$, and it is minimum in the case of $\mathrm{CF}-\mathrm{Fe}_{3} \mathrm{O}_{4}-\mathrm{ZnO}$. If the values of electrical conductivity and real permittivity are compared, both are in agreement with each other. The real part of complex permittivity is an expression of the polarization ability of the foam, which mainly arises from dipolar polarization and interfacial polarization. $^{36}$ In the case of CF-U, due to its higher value of conductivity, interfacial and dipole polarization contribute to its overall polarization capability. ${ }^{37}$ However, imaginary permittivity shows an opposite trend; imaginary permittivity has a maximum in the case of $\mathrm{CF}-\mathrm{Fe}_{3} \mathrm{O}_{4}$ and a minimum in the case of CF-U, which is related to losses. The decrease in permittivity with increasing frequency could be ascribed to the decreasing capacity of the dipoles to sustain in-phase movement with a rapidly pulsating electric vector of the incident radiation.

However, in the cases of $\mathrm{CF}-\mathrm{Fe}_{3} \mathrm{O}_{4}$ and $\mathrm{CF}-\mathrm{Fe}_{3} \mathrm{O}_{4}-\mathrm{ZnO}$, due to the lower value of conductivity, the interfacial polarization effect is comparatively small and as a result the value of real permittivity is lowered. Therefore, their impedance is considerably closer to the impedance of free space due to a lower value of real permittivity, which minimizes reflectivity. Thus, they become highly capable of absorbing EM radiation rather than reflecting it. The higher the value of the imaginary component of permittivity, the larger is the loss in the material. A material with a low dielectric loss can store energy, but will not dissipate the stored energy. A material with high dielectric loss does not store energy efficiently and a larger part of the energy of an incident wave is converted into heat within the material. Therefore, materials with a lower value of conductivity exhibit a large amount of losses that inhibit the propagation of EM radiation, i.e., absorption losses are greater in the cases of $\mathrm{CF}-\mathrm{Fe}_{3} \mathrm{O}_{4}$ and $\mathrm{CF}-\mathrm{Fe}_{3} \mathrm{O}_{4}-\mathrm{ZnO}$.
The $\varepsilon^{\prime \prime}$ value of carbon foam CF-U varies with frequency and it is lower than that of $\mathrm{CF}-\mathrm{Fe}_{3} \mathrm{O}_{4}-\mathrm{ZnO}$. The following equation for $\mathrm{SE}_{\mathrm{A}}$ demonstrates that the absorption component depends on the magnetic permeability $\left(\mu^{\prime}\right)$ of the material.

$$
\mathrm{SE}_{\mathrm{A}}=-8.68 t\left\{\left(\sigma_{\mathrm{T}} \omega \mu^{\prime}\right) / 2\right\}^{1 / 2}
$$

The CFoam CF-U does not show any magnetization, and as a result CF-U exhibits an absorption component, which is lower as compared to that of $\mathrm{CF}-\mathrm{Fe}_{3} \mathrm{O}_{4}-\mathrm{ZnO}$. The absorption loss depends upon not only magnetic permeability but also conductivity and frequency. A material cannot always be absorption dominated in the entire frequency range, but the value of $\varepsilon^{\prime \prime}$ should be less than that of $\varepsilon^{\prime}$, as demonstrated in Fig. 6(a and b).

Thus, the higher value of real permeability is also responsible for the radiation absorption. In CFoam, the existence of interfaces between $\mathrm{Fe}_{3} \mathrm{O}_{4}$ nanoparticles and CFoam, $\mathrm{ZnO}$ nanoparticles and CFoam, and $\mathrm{Fe}_{3} \mathrm{O}_{4}$ and $\mathrm{ZnO}$ are responsible for interfacial polarization, which further contributes to dielectric losses. Interfacial polarization occurs in heterogeneous media due to the accumulation of charges at the interfaces and the formation of large dipoles. Ferromagnetic nanoparticles act as tiny dipoles, which become polarized in the presence of an EM field and result in better microwave absorption.

The maximum real permeability among all the CFoams is that of $\mathrm{Fe}_{3} \mathrm{O}_{4}$-coated foam. This is possibly due to the improvement in its magnetic properties, along with a parallel reduction in eddy current losses due to the ferromagnetic behaviour of the coating material, while real permeability is almost negligible in the case of CF-U due to the non-magnetic behaviour of CFoam. When the frequency of the applied field increases, magnetocrystalline anisotropy plays an important role $^{38}$ and induced magnetization starts to lag behind the applied field, resulting in magnetic losses. The anisotropic effect is considerably stronger in the case of $\mathrm{Fe}_{3} \mathrm{O}_{4}$ 
nanoparticles-coated foam, and as a consequence a large difference occurs between magnetization and the applied field, leading to enhanced magnetic losses. In the same fashion, the imaginary permeability (magnetic loss) varies with increasing frequency. The $\mathrm{Fe}_{3} \mathrm{O}_{4}$ particle coating on CFoam also leads to matching input impedance along with a reduction in skin depth, which also contributes towards the absorption of EM radiation. In the microwave range, the natural resonances in the $\mathrm{X}$-band can be attributed to the small size of $\mathrm{Fe}_{3} \mathrm{O}_{4}$ and $\mathrm{ZnO}$ nanoparticles in CFoams. The anisotropy energy of small-sized materials, especially on the nanoscale, would be higher due to the surface anisotropic field caused by the small-size effect. ${ }^{39}$ Higher anisotropy energy also contributes to the enhancement of microwave absorption. In the same manner, magnetic losses vary with frequency: in the case of $\mathrm{CF}-\mathrm{Fe}_{3} \mathrm{O}_{4}$, both the real and imaginary parts of complex permeability increase with frequency and it is maximum between 10 and $12 \mathrm{GHz}$, while in $\mathrm{CF}-\mathrm{U}$ and $\mathrm{CF}-\mathrm{Fe}_{3} \mathrm{O}_{4}-\mathrm{ZnO}$, it is constant with increasing frequency. This has a positive effect on the absorption of microwave radiation. The magnetic and dielectric coating on the surface of the CFoam leads to better matching of input impedance along with a reduction in skin depth. This contributes further to the increase in the absorption losses of foam.

Fig. 5(d) shows the total losses with increasing frequency, which is associated with the sum of both dielectric and magnetic losses. From Fig. 5(d), it is evident that the maximum total loss is in the case of $\mathrm{CF}-\mathrm{Fe}_{3} \mathrm{O}_{4}$, which is associated with the magnetic properties of $\mathrm{Fe}_{3} \mathrm{O}_{4}$, while in the case of $\mathrm{CF}-\mathrm{Fe}_{3} \mathrm{O}_{4}-\mathrm{ZnO}$, it is associated with magnetic as well as dielectric losses. This clearly shows that the total loss in the case of $\mathrm{CF}-\mathrm{Fe}_{3} \mathrm{O}_{4}-\mathrm{ZnO}$ is less than in that of $\mathrm{CF}-\mathrm{Fe}_{3} \mathrm{O}_{4}$, which reveals that magnetic losses are dominant in the increase in SE due to the greater contribution of ferromagnetic material. This shows that the SE is dominated by magnetic losses. This fact is verified by measuring the magnetic properties by VSM.

Fig. 7 shows the room-temperature magnetization plot of CFoams, namely, $\mathrm{CF}-\mathrm{U}, \mathrm{CF}-\mathrm{Fe}_{3} \mathrm{O}_{4}$ and $\mathrm{CF}-\mathrm{Fe}_{3} \mathrm{O}_{4}-\mathrm{ZnO}$. The

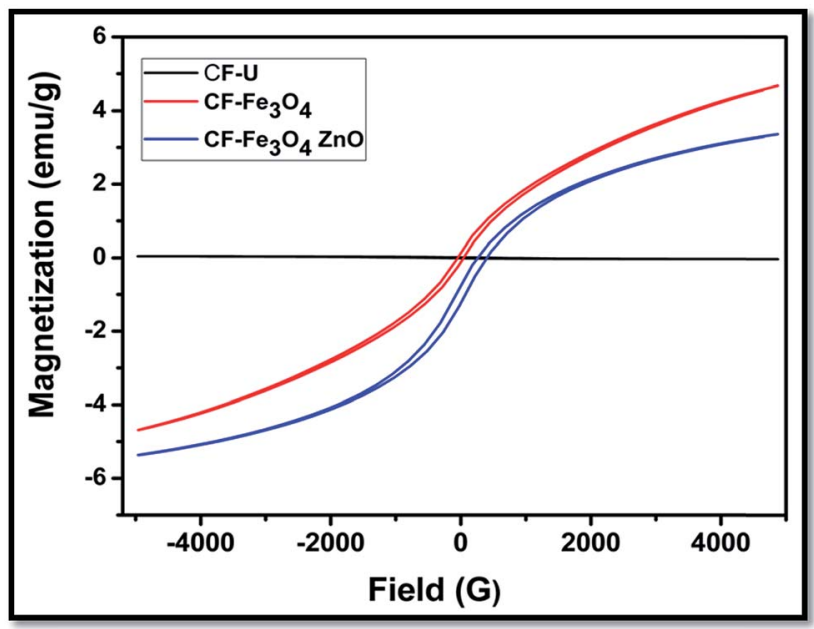

Fig. 7 Magnetization plot of CFoams $\mathrm{CF}-\mathrm{U}, \mathrm{CF}-\mathrm{Fe}_{3} \mathrm{O}_{4}$ and $\mathrm{CF}-\mathrm{Fe}_{3} \mathrm{O}_{4}-\mathrm{ZnO}$.

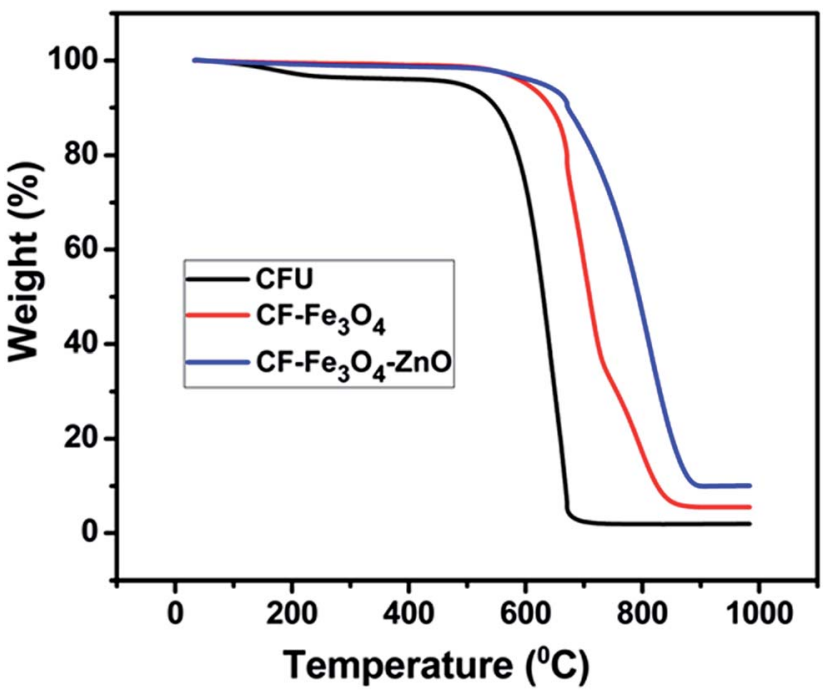

Fig. 8 Thermal stability of CFoam in oxidative (air) atmosphere.

magnetization data reveals that CF-U does not display any magnetization throughout the magnetic field because its carbon is in the amorphous phase with high electrical conductivity due to delocalized $\pi$ electrons. However, $\mathrm{Fe}_{3} \mathrm{O}_{4}$ and $\mathrm{Fe}_{3} \mathrm{O}_{4}-\mathrm{ZnO}$-coated CFoam display a narrow hysteresis loop. $\mathrm{CF}-\mathrm{Fe}_{3} \mathrm{O}_{4}$ possesses a saturation magnetization of $4.68 \mathrm{emu} \mathrm{g}^{-1}$ at $4.9 \mathrm{kG}$ and $\mathrm{CF}-\mathrm{Fe}_{3} \mathrm{O}_{4}-\mathrm{ZnO}$ possesses a saturation magnetization of $3.36 \mathrm{emu}^{-1}$. The higher saturation magnetization in the case of $\mathrm{CF}-\mathrm{Fe}_{3} \mathrm{O}_{4}$ is due to the magnetic properties of $\mathrm{Fe}_{3} \mathrm{O}_{4}$. These results are in agreement with the data for magnetic permeability and shielding effectiveness.

The thermal stability of the CFoam, as investigated by TGA in an oxidative (air) atmosphere, is depicted in Fig. 8. The thermal stability of CFoam depends on the structure of carbon; a graphitic structure possesses higher thermal stability as compared with non-graphitic carbon. ${ }^{40}$ It is observed that coated CFoams $\left(\mathrm{CF}-\mathrm{Fe}_{3} \mathrm{O}_{4}\right.$ and $\left.\mathrm{CF}-\mathrm{Fe}_{3} \mathrm{O}_{4}-\mathrm{ZnO}\right)$ possess higher thermal stability as compared to CF-U. The coating of $\mathrm{Fe}_{3} \mathrm{O}_{4}$ and $\mathrm{ZnO}$ enhances the thermal stability of CFoam by $\sim 100{ }^{\circ} \mathrm{C}$. In the case of CF-U, weight loss started from a temperature of $\sim 500{ }^{\circ} \mathrm{C}$ and total weight loss continued up to $650{ }^{\circ} \mathrm{C}$, while in the cases of $\mathrm{CF}-\mathrm{Fe}_{3} \mathrm{O}_{4}$ and $\mathrm{CF}-\mathrm{Fe}_{3} \mathrm{O}_{4}-\mathrm{ZnO}$, weight loss started from $600{ }^{\circ} \mathrm{C}$. In an oxidizing environment, weight loss initiation takes place from chemically active sites available in $1000{ }^{\circ} \mathrm{C}$ heat-treated CFoam, which react with oxygen molecules. However, in the cases of $\mathrm{CF}-\mathrm{Fe}_{3} \mathrm{O}_{4}$ and $\mathrm{CF}-\mathrm{Fe}_{3} \mathrm{O}_{4}-\mathrm{ZnO}$, the coating of nano- $\mathrm{Fe}_{3} \mathrm{O}_{4}$ and $\mathrm{ZnO}$ causes interaction with chemically active sites during heat treatment. This is responsible for the improvement of thermal stability in $\mathrm{CF}-\mathrm{Fe}_{3} \mathrm{O}_{4}$ and $\mathrm{CF}-\mathrm{Fe}_{3} \mathrm{O}_{4}-\mathrm{ZnO}$ foams.

\section{Conclusions}

CFoam was developed by a sacrificial template technique using coal tar pitch as the carbon precursor, and it was decorated by $\mathrm{Fe}_{3} \mathrm{O}_{4}$ and $\mathrm{Fe}_{3} \mathrm{O}_{4}-\mathrm{ZnO}$ nanoparticles to improve its electromagnetic radiation absorption. It was observed that a small 
uptake ( $10 \%$ enhancement in density) of magnetic and dielectric nanoparticles coated on the conducting CFoam significantly influenced its EM radiation scattering. The nanoparticles coating not only improved EM radiation absorption but also enhanced the compressive strength and thermal stability of CFoam. The CFoam total $\mathrm{SE}$ is in the range of $-25 \mathrm{~dB}$, which increases to -54 and $-56 \mathrm{~dB}$ after $\mathrm{Fe}_{3} \mathrm{O}_{4}$ and $\mathrm{Fe}_{3} \mathrm{O}_{4}-\mathrm{ZnO}$ nanoparticles coating, respectively. The increase in SE is due to absorption losses, which contribute -42 and $-45 \mathrm{~dB}$, respectively. The EM radiation absorption enhancements in the cases of $\mathrm{Fe}_{3} \mathrm{O}_{4^{-}}$and $\mathrm{Fe}_{3} \mathrm{O}_{4}-\mathrm{ZnO}$-decorated CFoam are mainly due to magnetic losses, which is verified by data for complex permittivity and permeability, and magnetic properties measured by a vibration sample magnetometer. The maximum complex permittivity and magnetization are observed in the case of $\mathrm{Fe}_{3} \mathrm{O}_{4}$-coated CFoam as compared to the others. This shows that the improvement in the absorption of EM radiation is mostly due to magnetic losses. A thermogravimetric study reveals that $\mathrm{Fe}_{3} \mathrm{O}_{4}$ and $\mathrm{Fe}_{3} \mathrm{O}_{4}-\mathrm{ZnO}$ coating improves the thermal stability of CFoam by $100{ }^{\circ} \mathrm{C}$. This clearly demonstrates that a small uptake of $\mathrm{Fe}_{3} \mathrm{O}_{4}$ and $\mathrm{Fe}_{3} \mathrm{O}_{4}-\mathrm{ZnO}$ nanoparticles coated on conducting CFoam is significantly useful for making it a RAM for sheath technology applications.

\section{Acknowledgements}

Authors are highly grateful to Director, CSIR-NPL, for his kind permission to publish the results. Authors would like to thank Dr S. K. Dhawan, Polymeric \& Soft Materials Section, for the measurement of EMI shielding. The authors are thankful to Dr R. K. Kotnala for magnetic properties measurement and Dr R. P. Pant, for providing ferrofluid suspension. Moreover, authors are grateful to $\mathrm{Mr}$ Jai Tawale for providing help in SEM characterization.

\section{References}

1 M. S. Pinho, M. L. Gregori, R. C. R. Nunes and B. G. Soares, Eur. Polym. J., 2002, 38, 2321-2327.

2 I. S. Seo, W. S. Chin and D. G. Lee, Compos. Struct., 2004, 66, 533-542.

3 K.-Y. Park, S.-E. Lee, C.-G. Kim and J.-H. Han, Compos. Sci. Technol., 2006, 66, 576-584.

4 J.-H. Oh, K.-S. Oh, C.-G. Kim and C.-S. Hong, Composites, Part $B, 2004,35,49-56$.

5 R. A. Stonier, SAMPE J., 1991, 27, 9-17.

6 J. Klett, A. McMillan, N. Gallego and C. Walls, J. Mater. Sci., 2004, 39, 3659-3676.

7 M. Inagaki, T. Morishita, A. Kuno, T. Kito, M. Hirano, T. Suwa and K. Kusakawa, Carbon, 2004, 42, 497-502.

8 F. C. Cowlard and J. C. Lewis, J. Mater. Sci., 1967, 2, 507-512. 9 C. Chen, E. B. Kennel, A. H. Stiller, P. G. Stansberry and J. W. Zondlo, Carbon, 2006, 44, 1535-1543.

10 M.-x. Wang, C.-Y. Wang, T.-Q. Li and Z.-J. Hu, Carbon, 2008, 46, 84-91.

11 T. Noda, M. Inagaki and S. Yamada, J. Non-Cryst. Solids, 1969, 1, 285-302.
12 R. Klett, High temperature insulating carbonaceous material, US 3914392 A, 1975.

13 R. Luo, Y. Ni, J. Li, C. Yang and S. Wang, Mater. Sci. Eng. A, 2011, 528, 2023-2027.

14 S. Wang, R. Luo and Y. Ni, Mater. Sci. Eng. A, 2010, 527, 33923395.

15 J. Klett, R. Hardy, E. Romine, C. Walls and T. Burchell, Carbon, 2000, 38, 953-973.

16 J. W. Klett, A. D. McMillan, N. C. Gallego, T. D. Burchell and C. A. Walls, Carbon, 2004, 42, 1849-1852.

17 Y. Chen, B.-Z. Chen, X.-C. Shi, H. Xu, Y.-J. Hu, Y. Yuan and N.-B. Shen, Carbon, 2007, 45, 2132-2134.

18 R. Kumar, S. R. Dhakate and R. B. Mathur, J. Mater. Sci., 2013, 48, 7071-7078.

19 R. Kumar, S. R. Dhakate, P. Saini and R. B. Mathur, RSC Adv., 2013, 3, 4145-4151.

20 R. Kumar, S. R. Dhakate, T. Gupta, P. Saini, B. P. Singh and R. B. Mathur, J. Mater. Chem. A, 2013, 1, 5727-5735.

21 M. Saitoh, T. Yamamoto, T. Sakamoto, H. Niori, M. Chino and M. Kobayashi, Ferroelectrics, 2001, 263, 9-12.

22 J. L. Kirschvink, Bioelectromagnetics, 1996, 17, 187-194.

23 D. K. Kim, M. S. Amin, S. Elborai, S.-H. Lee, Y. Koseoglu, M. Zahn and M. Muhammed, J. Appl. Phys., 2005, 97, 10J510.

24 A. Yadav, R. Kumar, G. Bhatia and G. Verma, Carbon, 2011, 49, 3622-3630.

25 B. Wang, Q. Wei and S. Qu, Int. J. Electrochem. Sci., 2013, 8, 3786-3793.

26 H. El Ghandoor, H. Zidan, M. M. Khalil and M. Ismail, Int. J. Electrochem. Sci., 2012, 7, 5734-5745.

27 S. Y. Bae, C. W. Na, J. H. Kang and J. Park, J. Phys. Chem. B, 2005, 109, 2526-2531.

28 H. Itoh and T. Sugimoto, J. Colloid Interface Sci., 2003, 265, 283-295.

29 J. Yang, X. Liu, L. Yang, Y. Wang, Y. Zhang, J. Lang, M. Gao and M. Wei, J. Alloys Compd., 2009, 485, 743-746.

30 A. K. Zak, M. E. Abrishami, W. Majid, R. Yousefi and S. Hosseini, Ceram. Int., 2011, 37, 393-398.

31 W. Wu, Z. Zhu, Z. Liu, Y. Xie, J. Zhang and T. Hu, Carbon, 2003, 41, 317-321.

32 S. Dhakate and O. Bahl, Carbon, 2003, 41, 1193-1203.

33 Y. Yang, M. C. Gupta, K. L. Dudley and R. W. Lawrence, Adv. Mater., 2005, 17, 1999-2003.

34 X. Han and Y. Wang, J. Funct. Mater. Devices, 2007, 13, 529. 35 A. Nicolson and G. Ross, IEEE Trans. Instrum. Meas., 1970, 19, 377-382.

36 G. Burns, Solid State Physics, Academic Press, New York, 1985.

37 S. J. Penn, N. M. Alford, A. Templeton, X. Wang, M. Xu, M. Reece and K. Schrapel, J. Am. Ceram. Soc., 1997, 80, 1885-1888.

38 D. Dimitrov and G. Wysin, Phys. Rev. B: Condens. Matter Mater. Phys., 1995, 51, 11947.

39 A. P. Singh, M. Mishra, P. Sambyal, B. K. Gupta, B. P. Singh, A. Chandra and S. K. Dhawan, J. Mater. Chem. A, 2014, 2, 3581-3593.

40 S. Dhakate, P. Bahl and P. Sahare, J. Mater. Sci. Lett., 2000, 19, 1959-1961. 